\title{
Educação inclusiva: a importância da inclusão dos alunos com TEA no ambiente escolar*
}

\section{Andressa Cristina Bevenutti Gasparelo}

Faculdade Anhanguera de Bauru (FAB), Bauru - SP - Brasil. Graduanda em Pedagogia. E-mail: debevenutti@gmail.com

\section{José Anderson Santos Cruz}

Faculdade Anhanguera de Bauru (FAB), Bauru - SP - Brasil. Docente da graduação e pós-graduação. Doutorando em Educação Escolar pela Faculdade de Ciências e Letras, FCLAr/Unesp. Prof. Orientador e colaborador com a pesquisa. Professor bolsista FAAC/Unesp pelo Departamento de Ciências Humanas. Bolsista DS CAPES. E-mail: joseandersonsantoscruz@gmail.com

\section{Arielly Kizzy Cunha}

Universidade Estadual Paulista (UNESP), Bauru - SP - Brasil. Doutoranda do Programa de Pós-Graduação em Mídia e Tecnologia da FAAC Unesp Bauru.

Profa. Coorientadora e colaboradora com a pesquisa. E-mail: ariellykizzy@gmail.com

\footnotetext{
*TEA Transtorno do Espectro Autista
} 


\section{Resumo}

Dentro do ambiente escolar é necessário que haja a inclusão de todos os alunos, independentemente de suas necessidades ou facilidades. Todos devem conseguir ter o direto de aprender coisas novas, explorar seu espaço físico e de ter socialização com os demais. Diante desse aspecto, torna-se dever da escola e do professor conhecer individualmente seus alunos para que consigam compreender aquilo que precisam para terem sua formação plena, para que seja efetivado o processo de ensino-aprendizagem. A utilização da adaptação curricular é excepcional para que aquele aluno consiga aprender o que o restante da classe está aprendendo, apenas de uma maneira diferenciada de acordo com o que ele necessite. Nesse sentido, essa pesquisa debruça no contexto da educação inclusiva com foco na atenção aos alunos com TEA no ambiente escolar. Utilizou-se a pesquisa bibliográfica com levantamento de conceitos e dados acerca do tema. Desse modo, o problema de investigação deste trabalho tornou-se em como a educação pode contribuir com a inclusão e com o ensino-aprendizagem dos alunos com TEA, tendo como objetivo conhecer o papel do professor e da escola, a importância da inclusão desses alunos e a adaptação curricular. Conclui-se nesta pesquisa que a educação inclusiva é fundamental no ambiente escolar, garantindo o acolhimento e ensino dos alunos com TEA.

Palavras-chave: Inclusão; Ensino-aprendizagem; Adaptação curricular.

\section{Abstract}

All the students, in the school environment, need to be included regardless of their needs or facilities. Everyone is able to learn new things, explore their physical space and socialize with others. Observing this aspect, it becomes the duty of the school and the teacher to know their students individually so that they can understand what they need in order to have their sctive education, then that the teaching-learning process can be implemented. The use of curriculum adaptation is exceptional for those students be able to learn what the rest of the class is learning, only in a different way according to what they need. In this sense, this research is based on the context of inclusive education focusing on the attention to students with ASD in the school environment. The bibliographic research was used with survey of concepts and data about the theme.Thus, this project investigated how the school education could contribute with the ASD students inclusion and their uarning, regarding the cole of the school and the teachers in this scenario, the importance of incluse education and the school curriculum adaptation. With the realized, it was checked theat the inclusive education is crucial in the school envivonnent, because it assures the greetinh and teaching of theASD students.

Keywords: Inclusion; Teaching and learning; Curriculum adaptation 


\section{Introdução}

A educação é um direito que todas as crianças possuem, assegurado pelo ECA (Estatuto da Criança e do Adolescente), de acordo com o Artigo 53 da Lei n8.069, que determina que todas as crianças e adolescentes possuem direito à educação e permanência no ambiente escolar. É necessário que todas as crianças tenham sua participação e inclusão dentro do ambiente escolar, não importando suas condições financeiras, dificuldades ou facilidades, sejam elas físicas, cognitivas, sensoriais ou comportamentais. Dentro desse conceito, é fundamental destacar a importância de uma participação ativa da escola e do professor em todo esse processo. A interação que a criança tem com a escola é fundamental para o seu desenvolvimento, sendo assim, torna-se necessário conhecer cada aluno individualmente, pertencendo ao professor o papel de mediador do conhecimento, adaptando as atividades propostas de acordo a necessidade de cada aluno, sempre respeitando o conteúdo que o restante da turma está aprendendo.

Dentro do ambiente escolar, toda criança deve receber os cuidados necessários para que consiga sempre aprender coisas novas, socializar-se e interagir-se uma com as outras, não importando sua condição financeira, física ou psicológica. Compreender quais são os papéis da escola e do professor é extremamente importante, uma vez que os alunos dependem desse processo para sua formação plena. A educação inclusiva proporciona a todo aluno o direito de estar incluso em um ambiente escolar, recebendo métodos que sejam capazes de atender suas demandas.

$\mathrm{Na}$ educação atual, é possível perceber que ainda há escolas e/ou professores que não proporcionam a devida inclusão dos alunos, sendo que, dentro do ambiente escolar, todas possuem o direito de aprender, socializar, participar de diferentes atividades dentro ou fora de sala de aula, e, de serem mediadas pelo professor caso precisem de adaptações. Diante disso, qual a importância da educação inclusiva e participação dos alunos com TEA, e qual o papel do professor e da escola nesse contexto?

Neste trabalho, tem-se como objetivo entender a importância da educação inclusiva. Para isso, é relevante descrever os conceitos mediante publicações já existentes acerca do tema, desse modo, compreender quais são os deveres do professor e da escola no processo de inclusão dos alunos com TEA; analisar a importância da adaptação do 
currículo, para que ocorra o total entendimento do aluno, a participação e socialização de todos dentro e fora de sala de aula.

O presente trabalho utilizou-se da revisão bibliográfica, acerca da Educação Inclusiva, buscando entender e analisar quais são os deveres da escola e do professor nesse processo. Serão analisados os autores como, Sanches e Teodoro (2007), Carvalho (2005) e Piaget (1959), a Declaração de Salamanca (1994), pela Unesco, e artigos recentes de pesquisas sobre Educação Inclusiva. A busca se deu por palavras-chave: educação inclusiva, ensino-aprendizagem e adaptação.

\section{Fundamentação Teórica}

\section{Conceito e a importância da educação inclusiva}

A educação inclusiva é a responsável por incluir todos os alunos no ambiente escolar, buscando valorizar as diferenças e entender a necessidade de cada um individualmente, para que assim o professor consiga analisar cada dificuldade e barreira que seu aluno tenha para ter sua formação plena. A grande importância da inclusão é estabelecida pela formação, socialização e aprendizado de todos os alunos, inclusive daqueles que possuem alguma deficiência, síndrome ou dificuldade.

Diante dos pressupostos da educação inclusiva, tem-se como premissa que todas as crianças tenham a participação em um ambiente regular de ensino que lhes proporcione o desenvolvimento, a aprendizagem e a interação. $\mathrm{O}$ respeito é a base para a inclusão, sendo preciso colocar as diferenças como algo positivo, em que todos possam aprender, cada um dentro do seu ritmo e de suas necessidades.

O princípio fundamental das escolas inclusivas consiste em todos os alunos aprenderem juntos, sempre que possível, independentemente das dificuldades e das diferenças que apresente. Estas escolas devem reconhecer e satisfazer as necessidades diversas dos seus alunos, adaptando-se aos vários estilos e ritmos de aprendizagem, de modo a garantir um bom nível de educação para todos, através de currículos adequados, de uma boa organização escolar, de estratégias 
pedagógicas, de utilização de recursos e de uma cooperação com as respectivas comunidades. É preciso, portanto, um conjunto de apoios e de serviços para satisfazer o conjunto de necessidades especiais dentro da escola. (UNESCO, 1994, p. 11-12)

As escolas devem proporcionar aos alunos sua formação plena, desde o aprendizado dos conteúdos até a socialização com as demais crianças, reconhecendo separadamente as necessidades de cada uma, podendo assim, fazer as adequações necessárias.

[...] de modo que se tornem espaços de formação e de ensino de qualidade para todas as crianças, mesmo aquelas que apresentam necessidades próprias e diferentes das demais crianças no domínio das aprendizagens correspondentes a sua idade e requerem recursos pedagógicos e metodologias educacionais específicas. (MONTEIRO, RIBEIRO, 2019, p. 731)

A educação inclusiva é essencial para que haja a socialização de todos os alunos dentro do ambiente escolar "[...] muitos pensam que a inclusão escolar é para os jovens em situação de deficiência, mas não, ela deve contemplar todas as crianças e jovens a quem são atribuídas necessidades educativas”. (SANCHES; TEODORO, 2007, s/p.).

Entretanto, há vários desafios para que a educação inclusiva seja uma realidade dentro das escolas brasileiras, é preciso muitas mudanças, e, uma delas é a formação e a metodologia que o professor utiliza dentro de sala de aula.

No Brasil, a formação de professores e demais agentes educacionais ligados à educação segue ainda um modelo tradicional, inadequado para suprir as reivindicações em favor da educação inclusiva. Vale destacar que, dentre os cursos de Pedagogia e de Pedagogia com habilitação em Educação Especial, poucos são aqueles que oferecem disciplinas ou conteúdos voltados para a educação de pessoas com necessidades especiais. (PLETSCH, 2009, p. 150) 
Para o professor ter uma visão ampliada sobre o que é a diversidade e de como trabalhar com alunos que necessitam de adaptações nas atividades a serem realizadas, é preciso que ele tenha um conhecimento prévio em sua graduação, mostrando como conseguir incorporar o ensino-aprendizado em todos os alunos presentes dentro de sua sala de aula. Atualmente, ainda há um índice alto de professores em sua formação inicial ou continuada os quais não tenham aprendido a trabalhar com alunos com deficiência dentro do ambiente escolar. (MANZINI, 2018).

De acordo com Carvalho (2005), a maior dificuldade da educação inclusiva está dentro da sala de aula, de como o professor irá adaptar os conteúdos que devem ser passados aos alunos, tendo o objetivo de gerar conhecimento em todos, respeitando suas limitações e necessidades; entretanto, esse desafio pedagógico é o que fará com que o aluno consiga a real inclusão dentro das aulas.

Mas, o maior desafio está nas salas de aula onde o processo ensinoaprendizagem ocorre de forma sistemática e programada. A grande questão parece ser: como planejar e desenvolver práticas pedagógicas verdadeiramente inclusivas, de modo a atender a todos e a cada um, valorizando o trabalho na diversidade, entendida como um recurso e não como obstáculo? $\mathrm{O}$ que nos falta para desenvolver práticas pedagógicas com direção inclusiva? (CARVALHO, 2005, p. 05)

A interação social entre as crianças é tão importante quanto o conteúdo que é apresentado pelo professor, é com ela que o aluno encontrará seu papel e sua importância perante a sociedade em que vive, portanto, a inclusão não é apenas estar presente fisicamente em um lugar, mas sim, de corpo e alma. (PIAGET, 1959)

Trata-se de mudança nos conceitos e nas práticas. E, como mudanças não ocorrem no vácuo, nem de um dia para outro, precisamos analisar nossas próprias atitudes frente à diferença, pois as transformações devem se processar a partir de nós mesmos. Igualmente, precisamos 
rever nosso entendimento sobre o papel das classes e das escolas especiais. (CARVALHO, 2011, p.04)

Todo e qualquer indivíduo, dentro da sociedade, precisa estar constantemente observando suas próprias atitudes e conceitos sobre o outro, modificando-as e transformando-as, colocando sempre o respeito às diferenças em primeiro lugar, sem julgar qualquer indivíduo, principalmente dentro do processo de ensino-aprendizagem.

A educação inclusiva garante que cada aluno seja mediado de maneira individual, de forma que o professor irá conhecê-lo e fazer adaptações de acordo com aquilo que ele necessite para ter sua formação plena, garantindo também a inclusão de todos os alunos em atividades em todos os espaços físicos dentro da escola "[...] reconhecer e responder as necessidades diversas de seus alunos acomodando ambos os estilos e ritmos de aprendizagem e assegurando uma educação de qualidade a todos através de um currículo apropriado" (UNESCO, 1994).

O currículo é uma ferramenta que pode e deverá ser modificado pelo professor para que ele consiga atender às necessidades do aluno, fazendo com que todos tenham condições de aprender, interagir e explorar os conteúdos que serão apresentados ao restante da sala.

Os direitos de aprendizagem todas as crianças e das com deficiência respeitando o desenvolvimento desse campo de experiência, expressos pelos verbos conviver, brincar, explorar, participar, comunicar e conhecer-se, sinalizam a categoria corpo e movimento como forma de expressão, de produção de sentidos e de experiências por parte das crianças. Assim sendo, esses direitos valorizam as crianças como produtoras de cultura, de conhecimentos e ratificam o entendimento de que essa categoria é fundamental na interação entre elas, fortalecendo a sua cultura de pares. (MONTEIRO; RIBEIRO, 2019, p. 741) 
Dentro do processo de inclusão, tanto a escola como o processor deverão respeitar os campos de desenvolvimentos, que são necessários para o aprendizado de todos os alunos, assim como, o respeito com a importância da interação entre eles.

Transtorno do Espectro Autista (TEA): deveres do professor e da escola no processo de inclusão

O Transtorno do Espectro Autista (TEA) é compreendido por um conjunto de transtornos neurodesenvolvimentais que trazem prejuízo, geralmente, nas relações sociais com o outro, na comunicação falada e nas manifestações de comportamento e/ou interesses. Esses aspectos, consequentemente, interferem em sua participação nos diferentes contextos sociais.

O termo espectro é utilizado para explicar a variação de intensidade e amplitude de alguns sintomas, sendo muito utilizado na psiquiatria moderna. Desta forma, usa-se o termo transtornos do espectro do autismo tratando-se, portanto, de um grupo heterogêneo de doenças do desenvolvimento que incluem prejuízos nas áreas sociais e de interação, linguagem, padrões de comportamento e interesses restritos em atividades repetitivas. (FIORINI, 2017, p. 17)

O autismo possui diversos níveis de intensidade, que podem variar de acordo com as características que a criança apresenta, ou seja, essa síndrome não existe um padrão a ser seguido, cada caso deve ser observado e tratado individualmente, levando em conta quais áreas a criança apresenta maior dificuldade ou restrição. " O TEA é considerado um transtorno que vai além da sua complexidade, distante de ser definido com exatidão, pois não existem meios pelos quais se possa testá-lo, muito menos medilo. " (ONZINI, GOMES, 2015) 
As crianças que possuem TEA podem apresentar um grande interesse por determinados objetos e/ou parte deles, que normalmente são desconsiderados por crianças da mesma faixa etária. O objeto torna-se mais interessante pelos estímulos que podem proporcionar, do que pela sua funcionalidade em si.

Ocorrem também disfunções no processamento sensorial diante de estímulos do ambiente; relações incomuns com as pessoas, comportamentos restritos, repetitivos e estereotipados, interesses em tarefas ou atividades restritas e a criança pode não utilizar de modo funcional os objetos ou brinquedos. (FIORINI, 2017, p. 24)

Os autistas podem possuir hipersensibilidade a estímulos visuais ou auditivos presente em um determinado ambiente, característica que também podem variar de criança por criança. Uma pode apresentar alta fascinação por cores vibrantes e determinados barulhos, e outra apresentar grande desconforto quando exposta as mesmas situações.

Segundo Monteiro e Ribeiro (2018), a inclusão está na importância da participação, integração e cooperação com todos os indivíduos, não importando sua condição física, mental ou comportamental. A pessoa que possuí qualquer tipo de deficiência ou transtorno como o TEA, também deve ser inclusa em todos os ambientes da sociedade, onde tenha o direito de ter as mesmas experiências e de ter sua cultura respeitada.

A Lei 12.764 é regulamentada pelo Decreto 8.368/14 que qualifica a pessoa com TEA como pessoa com deficiência para fins e efeitos legais, o que repercute na aplicabilidade integral das disposições da Lei 13.146/2015, que cria o Estatuto da Pessoa com Deficiência, destinado a assegurar e a promover, em condições de igualdade, o exercício dos direitos e das liberdades fundamentais por pessoa com deficiência, visando à sua inclusão social e cidadania. (MELO, SANTIAGO, 2018, p. 897) 
Após a regulamentação dessas leis, passou a ser obrigatória a participação e inclusão dos alunos com TEA em todos os ambientes públicos, assim como também nas escolas, onde elas devem ser inclusas e terem o direito de aprender e socializar com as demais crianças e professores. Torna-se papel do professor e da escola implantarem e educarem essas crianças, se adaptando e aprendendo com as suas limitações e peculiaridades.

Dentro do ambiente escolar, os alunos com TEA, na maioria das vezes, necessitam de uma atenção maior por parte da escola e do professor na questão da socialização e interação com os demais. Nesse momento, entra o papel da inclusão, em que é garantido que aquele aluno não estará somente presente dentro da sala de aula, mas sim, terá condições de interagir com tudo e todos a sua volta, proporcionando a aprendizagem que o professor pretende passar,

A escola deve ser um espaço que valorize a diversidade dos sujeitos e que utilize de propostas e alternativas para que essas crianças sejam verdadeiramente incluídas, valorizadas e acolhidas. Ao contrário, serão apenas mais situações cotidianas em que suas potencialidades não são reconhecidas, tampouco estimuladas ao longo da vivência escolar. (SALTO, CARNEIRO, 2019, p. 856)

A escola detém a responsabilidade de proporcionar diversos estímulos e aprendizados, visando à formação plena de todos os alunos matriculados. Para que isso ocorra, é necessário que ela implemente novas alternativas e se molde de acordo com as demandas de cada criança, para que todas tenham as mesmas condições dentro do ambiente escolar.

O processo de inclusão está muito além de apenas ter alunos com deficiência ou transtornos dentro da sala de aula. Torna-se necessário que o professor busque conhecer as particularidades e diferenças de cada um, encontrando maneiras para que cada criança 
consiga adquirir novos conhecimentos e assim, alcançar os mesmos objetivos do restante da sala.

Cada aluno autista é diferente do outro e que possui diferentes dificuldades e capacidades. Assim, é fundamental o professor incluir novas alternativas de ensinar esses alunos, trazendo práticas pedagógicas que consiga fazê-los socializar e interagir a partir de trocas de experiências com seus pares. Proporcionando, assim, um trabalho de desenvolvimento social, efetivo e intelectual do aluno com autismo, além do trabalho interativo de inclusão efetiva. (MONTEIRO, RIBEIRO, 2018, p. 915)

Dentro do processo de ensino-aprendizado dos alunos com TEA, o professor deve implementar novas alternativas em suas aulas para que esse aluno tenha condições de aprender e interagir tanto quanto os demais alunos. As diferenças presentes em cada criança devem passar a ser vistas como algo positivo, uma vez que ninguém é igual a ninguém. $\mathrm{O}$ contato entre as crianças ajudará muito no desenvolvimento e na prevenção de preconceitos futuros com pessoas que possuam alguma deficiência ou transtorno.

\section{A importância da adaptação curricular no processo de ensino aprendizagem}

A educação inclusiva garante que todos os alunos tenham condições para participar, socializar e aprender dentro do ambiente escolar, porém, cada um possui suas diferenças e peculiaridades, fator que deve ser analisado pelo professor, fazendo-o conseguir propor novas atividades. A partir das necessidades e diferenças de seus alunos, o professor deve elaborar planos de aulas diferenciados, adaptando-os e incorporando no currículo o mesmo objetivo de aprendizagem que o restante da sala terá que atingir, apenas de uma maneira diferente ou simplificada.

Aos professores, por sua vez, cabe atuar, em cooperação, compartilhando o conhecimento de que dispõem, para responder e 
atender às necessidades educacionais de todos os alunos, inclusive às dos alunos com deficiência, garantindo-lhes o acesso e permanência nos sistemas de ensino. (ARANHA, 2005, p. 19)

Perante as necessidades que cada aluno possui dentro do ambiente escolar, o Ministério da Educação busca, por meio de documentos, mostrar e exemplificar a importância da adaptação curricular, mostrando ao professor como ele deverá agir diante das dificuldades de seus alunos e quais estratégias de ensino serão possíveis usufruir para que haja o efetivo ensino-aprendizagem para todos os presentes em sala de aula.

A adaptação curricular é uma maneira que o professor encontrará de conseguir atingir com sucesso o processo de ensino-aprendizagem em todos os alunos, mas, para que isso ocorra, deverá conhecer cada um deles individualmente, para entender como deverá ensinar-lhes para que aprenda. “[...] reconhecer a possibilidade de especificidades individuais que se apresentam e que demandam situações alternativas para a apreensão e produção dos conhecimentos.” (ANJOS; SILVA; SILVA, 2019, p.652)

A partir do conhecimento de seu aluno, o professor poderá elaborar o currículo de forma que atenda às necessidades que cada um precisa para ter sua formação plena, utilizando estratégias diferenciadas para um ensino individualizado, tendo uma metodologia eficaz para o restante dos alunos fazendo-os colaborarem na interação com os demais. (RIBEIRO; MONTEIRO, 2019)

Conhecer a rotina significa observar as particularidades dos alunos, de que modo participam das atividades, quais habilidades apresentam e também quais são as dificuldades relacionadas à sua inclusão no contexto escolar. Tais aspectos podem contribuir de forma mais precisa para o direcionamento e planejamento de práticas que favorecerão a inclusão do aluno [...] (FIORINI, 2017, p. 48)

O processo de ensino-aprendizagem é determinado pela maneira como o professor irá ensinar os conteúdos pré-estipulados e aquilo que efetivamente o aluno irá 
aprender desses conhecimentos. Esse processo é uma via de mão dupla, dependendo do professor e do aluno, e ambos deverão se adaptar a mudanças, quando necessário.

Podemos entender com Programa Educativo Individual (PEI) o conjunto de decisões gerais sobre as respostas educativas mais adequadas para determinado aluno, tendo em conta os resultados da avaliação especializada, a qual decorre, por sua vez, da avaliação dos docentes em sala de aula, que dá origem ao processo de referenciação ou sinalização. (LEITE, 2011, p. 30)

O Programa Educativo Individual (PEI) é uma alternativa que o professor poderá utilizar para atender todos os alunos. Através dele poderá conhecer as diferenças de cada um dentro de sala de aula, buscando melhores métodos de ensino para aquela criança. O PEI será um indicador para determinar quais serão as melhores alternativas para o aprendizado daquele aluno por meio dos resultados analisados.

$\mathrm{O}$ processo de ensino-aprendizagem depende diretamente da maneira como o professor irá ensinar os conteúdos e de que maneira o aluno está recebendo e entendendo aquela matéria, ou seja, torna-se essencial o professor saber conhecer seu aluno individualmente, para que ele consiga analisar os pontos a serem trabalhados ou modificados a fim de que seus alunos atinjam os objetivos propostos para determinado período.

Desse modo, o PEI torna-se uma ferramenta de ensino essencial, pois através dele será possível que o professor planeje um plano de ensino e se adapte às necessidades que o aluno possua para aprender.

A adaptação curricular deve ser pensada de maneira que o aluno que necessite dessa modificação tenha chances de alcançar os mesmos conteúdos a serem apresentados para o restante da classe, apenas de uma maneira diferente ou facilitada para o seu total entendimento. "Os professores devem modificar a sua prática para atender as necessidades desses alunos, a fim de que as disciplinas para os alunos com necessidades educacionais especiais sejam as mesmas, só que adaptadas à necessidade de cada um.” (SILVA, ARRUDA, 2014, p.22) 
Com a adaptação curricular, o professor consegue se moldar ao aluno, entendendo o que ele necessita para aprender, participar e socializar nas atividades propostas, tornando-se incluso naquele ambiente.

$\mathrm{Na}$ sociedade atual, um grande auxiliar no processo de ensino-aprendizagem é o uso da tecnologia no ambiente escolar, uma vez que ela é capaz de facilitar tanto na maneira como o professor ensina como também auxilia no aprendizado do aluno. Dentro do contexto da educação inclusiva e adaptação curricular, é possível se deparar com a Tecnologia Assistiva (TA), “[...] diz respeito à pesquisa, fabricação, uso de equipamentos, recursos ou estratégias utilizadas para potencializar as habilidades funcionais das pessoas com deficiência.” (BRASIL, 2009, p. 12]

A TA é uma maneira que a escola e o professor podem utilizar para facilitar o aprendizado dos alunos que possuem alguma deficiência ou dificuldades de movimentos. Essa tecnologia consegue se adaptar a necessidade que o aluno possua, seja ela física, motoro ou intelectual.

A Tecnologia Assistiva (TA) surge, para a pessoa com deficiência como um privilegiado elemento na construção de novos caminhos e possibilidades para o aprendizado e desenvolvimento, na medida em que se situa com instrumento mediador, disponibilizando recursos para superar suas barreiras de aprendizagem e participação e permitindo que esta possa interagir, relacionar-se e competir em seu meio com ferramentas mais poderosas, proporcionadas pelas adaptações de acessibilidade de que dispõe. (MELO, SANTIAGO, 2018, p. 901)

Dentro do ambiente escolar não existe apenas um método único e eficaz para o aprendizado dos alunos, pelo contrário, existem diversos fatores e recursos que podem ser utilizados dependendo das necessidades que ele tenha. Por isso torna-se tão fundamental a proximidade do professor com aquele que será mediado, pois assim conseguirá encontrar meio alternativos para conseguir ensinar aquilo que está prédefinido nos currículos, seja apenas pela adaptação curricular, pelo uso das TA, ou a junção de ambas, aquilo que o professor julgar primordial para alcançar o entendimento de seu aluno. 


\section{Considerações Finais}

Perante este trabalho, foi possível concluir a grande importância que a educação inclusiva possui dentro do ambiente escolar, observando e destacando os diretos que todos os alunos detêm, sendo que as diferenças entre cada um deles devem ser tratadas com respeito e dignidade, uma vez que a escola deve incorporar maneiras para que todos os alunos tenham condições de aprender e interagir com os demais, não importando suas dificuldades ou facilidades.

Tendo em vista os aspectos observados, o professor é um mediador do conhecimento, detentor do papel de incorporar todos os alunos no processo de ensinoaprendizagem, levando em consideração que cada aluno deve ser conhecido e trabalhado individualmente, de acordo com suas necessidades e facilidades. No caso dos alunos com TEA, o professor deverá encontrar meios para que esse aluno também tenha condições de aprender e socializar. Os alunos com TEA geralmente apresentam maior dificuldade na área de socialização com os demais, aspecto que o professor deverá intervir para que aconteça da melhor maneira possível. Diante desse aspecto, é possível destacar, também, que a inclusão deve partir de todos os membros da escola, não somente dos professores.

Diante da necessidade de o professor conhecer individualmente e de trabalhar de acordo com as necessidades de cada aluno, foi possível entender e compreender a grande importância que a adaptação curricular tem no processo de ensinoaprendizagem.

A adaptação curricular é uma maneira que o professor pode e deve utilizar para garantir que seu aluno tenha condições de aprender dentro de suas limitações. Esse instrumento possibilita que o professor faça adaptações necessárias para que o aluno tenha condições de aprender, sempre respeitando os assuntos que estão sendo trabalhados com o restante da sala, apenas de uma maneira diferente.

AGRADECIMENTOS: À Faculdade Anhanguera de Bauru. À CAPES. 


\section{Referências}

ANJOS, Cleriston Izidro dos; SILVA, Shirley; SILVA, Cleber Nelson de Oliveira. Políticas, formação docente e práticas pedagógicas: reflexões acerca de uma educação infantil inclusiva. Revista Ibero-Americana de Estudos em Educação, [S.1.], p. 641655, may 2019. ISSN 1982-5587. Disponível em:

https://periodicos.fclar.unesp.br/iberoamericana/article/view/12196/8047. Acesso em: 01 oct. 2019.

ARANHA, Maria Salete Fábio. Projeto Escola Viva: garantindo o acesso e permanência de todos os alunos na escola: necessidades educacionais especiais dos alunos. Brasília: Ministério da Educação, Secretaria de Educação Especial, 2. ed. Brasília, 2005.24p

BRASIL. Constituição da República Federativa do Brasil: promulgada em 5 de outubro de1988. Organização do texto: Juarez de Oliveira. 4. ed. São Paulo: Saraiva, 1990. 168 p. (Série Legislação Brasileira).

BRASIL. Lei no 8.069, de 13 de julho de 1990. Dispõe sobre o Estatuto da Criança e do Adolescente e dá outras providências. Diário Oficial [da] República Federativa do Brasil, Brasília, DF, 16 jul. 1990. Disponível em: http://www.planalto.gov.br/ccivil_03/LEIS/L8069.htm\#art266. Acesso em: 01 set. 2019.

BRASIL. Subsecretaria Nacional de Promoção dos Direitos da Pessoa com

Deficiência. Comitê de Ajudas Técnicas. Tecnologia Assistiva. - Brasília: CORDE, 2009. $138 \mathrm{p}$.

CARVALHO, Rosita Edler. Educação inclusiva: do que estamos falando? Revista Educação Especial, Santa Maria, p. 19-30, dez. 2011. ISSN 1984-686X. Disponível 
em: https://periodicos.ufsm.br/educacaoespecial/article/view/4395. Acesso em: 02 maio 2019.

CASTRO, Paula Almeida de; MATTOS, Carmen Lúcia Guimarães de. Sentidos da escola: fazeres, deveres e saberes. Revista Teias, [S.1.], v. 12, n. 25, p. 16 pgs., ago. 2011. ISSN 1982-0305. Disponível em: https://www.epublicacoes.uerj.br/index.php/revistateias/article/view/24167/17145. Acesso em: 01 oct. 2019.

FIORINI, Bianca Sampaio. O aluno com transtornos do espectro do autismo na educação infantil: caracterização da rotina escolar. Repositório digital UNESP. Marilia, 03 jul. 2017. 145 f. Disponível em: http://hdl.handle.net/11449/150463. Acesso em: 02 oct. 2019.

GALVÃO FILHO, T. A. A construção do conceito de Tecnologia Assistiva: alguns novos interrogantes e desafios. In: Revista da FACED - Entreideias: Educação, Cultura e Sociedade, Salvador: Faculdade de Educação da Universidade Federal da Bahia - FACED/UFBA, v. 2, n. 1, p. 25-42, jan./jun. 2013. Disponível em: http://www.galvaofilho.net/TA_desafios.htm

LEITE, Teresa. Currículo e Necessidades Educativas Especiais. Aveiro: Universidade de Aveiro. p. 59, 2011. Disponível em: http://hdl.handle.net/10400.21/2724. Acesso em: 03 oct. 2019

MANZINI, Eduardo José. Política de educação especial: considerações sobre públicoalvo, formação de professores e financiamento. Revista on line de Política e Gestão Educacional, [S.1.], p. 810-824, dec. 2018. ISSN 1519-9029. Disponível em: https://periodicos.fclar.unesp.br/rpge/article/view/11914/7797. Acesso em: 05 sep. 2019.

MELO, Sandra Cordeiro de; SANTIAGO, Mylene Cristina. Alunos com TEA como desencadeadores de processos formativos. Revista on line de Política e Gestão 
Educacional, [S.1.], p. 890-904, dec. 2018. ISSN 1519-9029. Disponível em: https://periodicos.fclar.unesp.br/rpge/article/view/11919/7802. Acesso em: 06 oct. 2019.

MONTEIRO, Solange Aparecida de Souza; RIBEIRO, Paulo Rennes Marçal. O lugar das crianças com deficiências na educação infantil e políticas de inclusão na educação brasileira. Revista Ibero-Americana de Estudos em Educação, [S.1.], p. 730-745, may 2019. ISSN 1982-5587. Disponível em:

https://periodicos.fclar.unesp.br/iberoamericana/article/view/12203/8053. Acesso em: 05 sep. 2019.

ONZI, Franciele Zanella; GOMES, Roberta de Figueiredo. TRANSTORNO DO ESPECTRO AUTISTA: A IMPORTÂNCIA DO DIAGNÓSTICO E REABILITAÇÃO. Revista Caderno Pedagógico, [S.1.], v. 12, n. 3, dez. 2015. ISSN 1983-0882. Disponível em: http://univates.br/revistas/index.php/cadped/article/view/979/967. Acesso em: 23 sep. 2019.

PEREIRA, Débora Mara. Análise dos efeitos de um plano educacional individualizado no desenvolvimento acadêmico e funcional de um aluno com transtorno do espectro do autismo. 2014. 181 f. Dissertação (Mestrado em Educação) - Universidade Federal do Rio Grande do Norte, Natal, p. 181, 2014.

PLETSCH, Márcia Denise. A formação de professores para a educação inclusiva: legislação, diretrizes políticas e resultados de pesquisas. Educação revista. Curitiba, n. 33, p. 143-156, 2009. Disponível em:

http://www.scielo.br/scielo.php?script=sci_arttext\&pid=S010440602009000100010\&lng=pt\&nrm=iso. Acesso em: 02 maio 2019. http://dx.doi.org/10.1590/S0104-40602009000100010.

PIAGET, J. A Linguagem e o Pensamento da Criança. Rio de Janeiro: Fundo de Cultura, 1959 
SALTO, Mariana Picchi; CARNEIRO, Relma Urel Carbone. A concepção docente em uma experiência de educação infantil inclusiva: um estudo de caso. Revista IberoAmericana de Estudos em Educação, [S.1.], p. 855-868, may 2019. ISSN 1982-5587. Disponível em:

https://periodicos.fclar.unesp.br/iberoamericana/article/view/12211/8061. Acesso em: 05 oct. 2019.

SANCHES, Isabel; TEODORO, António. Procurando indicadores de educação inclusiva: as práticas dos professores de apoio educativo. Revista Portuguesa de Educação, Braga, v.20, n.2, p.105-149, 2007. Disponível em: http://www.scielo.mec.pt/scielo.php?script=sci_arttext\&pid=S087191872007000200005\&lng=pt\&nrm=iso. Acesso em: 02 maio 2019.

UNESCO. Coordenadoria Nacional para a Integração da Pessoa Portadora de Deficiência (CORDE). Declaração de Salamanca de princípios, política e prática para as necessidades educativas especiais. Brasília: CORDE, 1994 